(C)The Pakistan Development Review

46 : 4 Part II (Winter 2007) pp. 971-984

\title{
Demand Analysis of Recreation Visits to Chitral Valley: A Natural Resource Management Perspective
}

\author{
MUHAMMAD RAFIQ and SHAFIQULLAH
}

\section{INTRODUCTION}

Recreational visits are primarily about human activity which involves travel from an originating area to a destination for cultural, economic, and social exchange processes. People travel to exotic locations for sight seeing, picnicking, bird watching, and for cultural and religious settings. However, accessibility to such areas is often free, which not only results in environmental hazards but also deprives the cash destitute government from revenue that such these sites offer.

Valuing the recreational benefits associated with a destination based on tourists' preferences can help formulate an appropriate policy for Natural Resource Management (NRM). Environmental and natural resource management studies often try to measure the welfare change associated with a policy change. Welfare is generally defined as area under the demand curve; accordingly, by estimating the demand curve, consumer surplus is obtained which shows the welfare changes associated with an environmental policy change [Gunatilake (2003)]. The recreational values thus obtained can be utilised for a cost benefit analysis of a policy option, thereby, managing a park or a natural resource on a sustainable basis.

Various valuation studies have been conducted in this regard e.g. Lumpinee Park by Grandstaff and Dixon (1995) and Khao Yai National Park by Kaosa-ard, et al. (1995). These studies were conducted in Thailand for estimating the parks values. Himayatullah (2004) had conducted a similar study in order to estimate the demand for ecotourism of Margallah Hills in Islamabad. Bhutan National Ecotourism Strategy (2002) adopted a new strategy of "High Value, Low Impact" tourism development strategy. Under the quantity vs. quality issue, the Bhutanese government put a fee of $\$ 200$ per person which raised the total cost curve in an effort to achieve an equilibrium number of visitors.

Pakistan in general and NWFP in particular possess many exotic locations, which attracts a large number of domestic and foreign tourists. This study was designed for the valuation of tourism benefit in Chitral Valley which offers composite tourism attractions ranging from nature based to religious and cultural products. The output includes the

Muhammad Rafiq<sufi92@hotmail.com> is Assistant Professor, Institute of Management Sciences, Peshawar. Shafiqullah <Shafiqbangash@hotmail.com> is Assistant Professor, University of Peshawar, Peshawar.

Authors' Note: We are thankful to the Higher Education Commission and the Institute of Management Sciences, Peshawar, for providing us financial support to carry out this study. 
derivation of demand curve and estimation of consumer surplus (which reveals the welfare of the tourists). The end results obtained can facilitate the authorities concerned in framing appropriate NRM policy.

\section{AREA PROFILE}

The Chitral valley at an elevation of 1127.76 meters (3,700 feet) is a picturesque resort, famous for it scenic beauty, and cultural attraction. It is a paradise for mountaineers, anglers, hunters, hikers, naturalists, and anthropologists. The Trichmir peak, which is the highest Peak of the Hindu Kush Mountains with an elevation of 7787.64 meters $(25,550$ feet), dominates this $321.87 \mathrm{~km}$ (200 miles) long exotic valley. Afghanistan is located to the north, south, and west of the district. A narrow strip of Afghan territory, Wakhan separates it from the ex-Soviet republic of Tajikistan. Tourists flock to Chitral from June to September. The rest of the year, this land is inaccessible because the traffic routes are blocked by snow. The area is accessible thorough air and land. The district capital is Chitral Town itself. The main attractions of Chitral Town are the bazaar, the Mahtar of Chitral's fort, and the main Mosque by the river. The summer palace of the ex-ruler of Chitral is on the hilltop above the town at Birmoghlasht.

Garam Chashma is another attraction of the valley. Visitors have to take a spectacular drive up the Latbo/Latkho River through deep and narrow gorges to reach this place. This unspoiled enchanting valley of orchards, verdant fields, and snow clad peaks is renowned for its boiling Sulphur springs which are famous for their healing effect on skin diseases, gout, rheumatism and chronic headaches.

One of the major attractions of Chitral are the Kalash valleys-the home of the Kafir-Kalash or 'Infidel Wearers of the Black Robe', a primitive pagan tribe. These are a non Muslim and culturally distinct tribe whose ancestry is shrouded in mystery. A legend has it that some soldiers of the legions of Alexander of Macedonia settled down in Chitral and their off-springs are the present Kafir-Kalash.

The most exciting polo tournament of the entire Northern Areas is played on top of the Shandur Pass, almost 4000 meters above sea level; a place unique and exotic in itself surrounded by some of the most spectacular mountain scenery in the world. The event marks the annual rivalry between the polo teams of Gilgit and Chitral. ${ }^{1}$

The valley is famous for its flora and fauna and is habitation for different species of birds and animals, for example the 'Markhor' or Ibex is found in these terrains. This place has rich history, cultural milieu and scenic beauty and therefore it offers different use and non-use values to the current and the future generations.

\section{THEORETICAL BACKGROUND}

The theoretical idea behind the valuation studies, using revealed preference or stated preference methods, is the determination of a demand curve for visits and calculation of consumer surplus which is the area under the demand curve. But unlike private goods, environmental goods have non-use values as well as well as indirect benifits, therefore if measured in direct cost such as entrance fee etc, may give inaccurate

pricing results by showing underestimation of the importance of good. Economists have

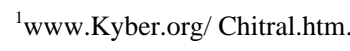


provided solution to this problem in terms of travel cost method (TCM) and contingent valuation $(\mathrm{CV})$ method.

Mc Connell (1992) has expounded the concept, which is expressed as:

Where:

$$
U=u(X, r, q)
$$

$U=$ utility

$X=$ the bundle of other goods (assumed to be a numeraire in the model)

$r=$ the number of visits to the site or visitation rate

$q=$ quality of site

The consumer faces the following budget constraint:

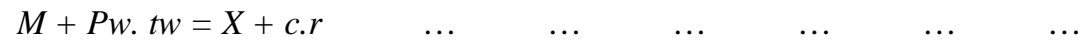

Where,

$$
\begin{aligned}
& M=\text { exogenous income } \\
& P w=\text { wage rate } \\
& t w=\text { hours of work } \\
& c=\text { monetary cost of trip }
\end{aligned}
$$

The Equation (1) implies that the total income of the visitor is spent on purchasing a bundle of other goods and recreation on the site, while income has two portions viz., exogenous and income earned by allocating all the available time for work. Exogenous income is any income other than wage income.

But in addition to the budget constraint, the visitor also faces the following time constraint:

$$
\begin{array}{lllllll}
t^{*}=t w+(t 1+t 2) r & \ldots & \ldots & \ldots & \ldots & \ldots & \ldots
\end{array}
$$

Where,

$$
\begin{aligned}
& t^{*}=\text { total discretionary time } \\
& t w=\text { hours of work } \\
& t 1=\text { round trip time } \\
& t 2=\text { time spent on site }
\end{aligned}
$$

The price of recreation $P r$, then includes the round trip monetary cost of travel to the site, the time cost of travel and the cost of time spent on the site, i.e. $\operatorname{Pr}=c+P w(t 1$ $+t 2$ ). The monetary cost of travel has two components; the entry fee (if any) and the cost of traveling. Entry fee if denoted by $f$ and remaining travel cost by $P d$. $d$, where $P d$ is the per kilometer travel cost and $d$ is the distance covered. The maximisation problem can be symbolised by putting Equation (2) in (1) and using the information is the above mentioned Para, as:

Max: $u(X, r, q)$

$S t: M+P w \cdot t^{*}=X+r[f+P d \cdot d+P w(t 1+t 2)]$

Using the Lagrangian function of the maximisation problem and solving it by taking the derivative w.r.t $X$ states that the visitor purchases other commodities up to a 
point where his marginal utility is equal to the marginal utility of money income time the price of other commodities (unity). $\lambda$ in the function would be marginal utility of income. While taking the derivative w.r.t $r$ would state that a visitor decides about number of visits to a site when the marginal utility of the visits would be equal to the full price of recreation time the marginal utility of the money income. Moreover, Equation (1) would become as:

$$
M+P w . t^{*}=X+r[f+P d . d+P w(t 1=t 2)] \quad \ldots \quad \ldots \quad \ldots \quad \ldots
$$

The equation equates visitor's income with expenditure.

Solution to the above mentioned equations requires derivation of the demand curve. The demand function can be represented as:

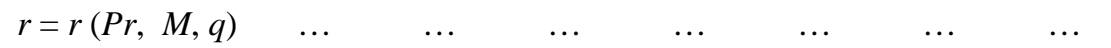

Travel Cost Method (TCM) is a means of determining the values the value of $r$ (or sometime it is denoted as VR). The idea was originally developed by Harold Hotelling in 1947. The basic premise is that although the actual values of the recreational experience does have a price tag, the costs incurred by individuals in travelling to the site makes it possible to estimate a demand curve for the site. There are two approaches to the travel cost method; the Individual Travel Cost Method (ITCM) and Zonal Travel Cost Method (ZTCM). The first method uses individual observation but entails frequent visits by the tourists and is very data sensitive.

Zonal Methods, on the other hand, utilises the averages of the variable by grouping the data into zonal data, for example, average zonal travel cost $\mathrm{TCz}$, average income to the zone, and visits per thousand of the population of the zone per year Vz. Therefore,

$\begin{array}{llllllll}V z=f(T C z, X 1, X 2) & \ldots & \ldots & \ldots & \ldots & \ldots & \ldots\end{array}$

The user fee, if any, is added to the travel cost. Zonal Method divides the area around the site into 'zones of origin' which primarily depends upon the distance travel or average distance from the site, or it can be administrative zones, or statistical zones etc. The method implicitly assumes that individuals coming from the same zone have same probability of travelling to the site and taste and other factors are assumed to be same for the zonal population [Lansdell and Gangadharan (2003)].

There is no theoretical agreement as to which method should be preferred; however, since the visitors travel to Chitral just once a year because of the distance, time and cost involved in traveling to the site, therefore, Zonal Travel Cost Method has been employed for the present study. The estimation of the Equation (6) provides only one data point, yet using the survey data and by varying the hypothetical entry fee, the remaining points on the demand curve are obtained.

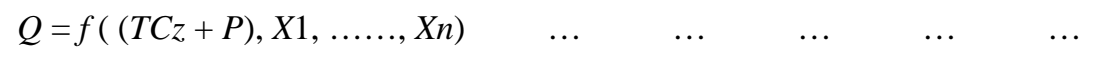

Where $Q=\mathrm{S} P o p z \mathrm{Vz}$ (population in thousand in each zone multiplied by the visitation rate per thousand for each zone per year and is defined as the aggregate demand for the area [Lansdell and Gangadharan (2003)].

This is the standard process of estimating the Marshallian demand curve [Gillespie (1997)]. The estimated equation can be used for predicting the change in the total 
visitation as a response to changes in the price of visitation. Moreover, the consumer surplus is obtained from the equation which is the fundamental principle of valuation provided by the TCM.

Several issues ensue with the application of zonal methods, for example, the appropriate cost to be included in the travel cost, treatment of time, multiple visits, substitute site, the choice of functional form, the choice of zones, and the demographic characteristics of the population.

Beal (1995) reported that most of the respondents considered the fuel, food, and accommodation cost as relevant to their trip cost. Walsh, Senders and McKean (1990) pointed out that including the round trip cost that is, the cost to and from the cost may be useful. For the present study, the round trip petrol costs and on site monetary costs reported by the respondents have been considered.

The inclusion of time cost is a subtle issue. McConnell (1992) argued that the time spent on the site is an important cost and should be included. Cesario (1978) supported the idea of including the time cost of traveling to a site. Smith et al. (1983) advocated that some proportion of the individual's wage should be included as a time cost. Cesario (1978) noted that in 1960s and 1970s the TCM studies used $1 / 4$ and $1 / 2$ proportion of wage as time cost. This study took the average of the opportunity cost question as reported by the respondent which gave a value of fifty percent of their incomes.

Multipurpose trips cause a problem of estimating the true cost of visiting a place. However, Chitral is an exquisite place and it was observed that the visitors exclusively travel to this valley for recreation purpose.

Prices of the substitute site is a important determinant of the recreational demand; however, visitors were unable to identify common substitute site, while many visitors reported that they don't consider any other resort to be the substitute of Chitral, hence this variable has not been incorporated.

The choice of functional form is arbitrary. Economic theory does not suggest any particular functional form. The commonly used forms are linear, quadratic, log linear, quadratic and double log form, however double log and linear form are the frequently used techniques (Ward \& Beal 2000). Many studied employed the double log method as it caters for the extreme value.

The selection of zone is a crucial stride and many studies have suggested that the zone should be selected by taking into account its implications on the travel cost. Yet, the considerations for the zone selection include the distance of an originating place from the site, the availability of data on income, education and the demographic characteristics. The zones should not be too large, otherwise, this may result in the loss of information and also these should not be too small which may result in zero visitation problems. Keeping in view the above mentioned requirements, our study has divided the data into five zones; these include the four provinces of the country as zones and the all the foreign visitors as fifth zones. Since the proportion of the foreign visitors to the total numbers of the tourists was 15 percent, therefore, we decided to retain them as fifth zones.

\section{MATERIAL AND METHOD}

The methods employed here can be traced back to 'gravity' models, which were used in general to model commuting decisions by regional economists. The rudiments of 
these models were apparent in Hotelling's (1949) Travel Cost Models (TCMs) which used the number of visitors from an origin zone as a dependent variable and travel costs from the zone as a key explanatory variable [Hanley, et al. (2001)]. TCMs subsequently evolved into trip generation functions (TGFs) which predicted an individual's demand for a recreational trip by including visitor and, later, site characteristics as explanatory variables. The approach adopted for this study is the Zonal Travel Cost. The zones have been selected based on travel time and distance from the site. These include four zones which are four provinces of Pakistan and fifth zone is the Rest of the World (Row) zones. Foreigners have been retained because according to the information acquired, foreigners constitute 14 percent of the total visitors. The zones used and the average distance travelled is shown in the Table 1.

Table 1

Zonal Statistics

\begin{tabular}{|c|c|c|c|c|c|c|c|}
\hline Zones & Average Age & $\begin{array}{l}\text { Average } \\
\text { Income }\end{array}$ & $\begin{array}{c}\text { Average } \\
\text { Distance } \\
(\mathrm{KM})\end{array}$ & $\begin{array}{c}\text { Average } \\
\text { Traveling } \\
\text { Time }\end{array}$ & $\begin{array}{c}\text { Average } \\
\text { Time Spent } \\
\text { on the Site }\end{array}$ & $\begin{array}{c}\text { Average } \\
\text { Travel Cost }\end{array}$ & $\begin{array}{l}\text { Visitation } \\
\text { Rate (VR) }\end{array}$ \\
\hline Balochistan & 35.25 & Rs.7 5000 & 1750 & $66 \mathrm{hrs}$ & 2 days & Rs.56505 & .01475 \\
\hline NWFP & 33.06 & Rs. 25000 & 400 & $17 \mathrm{hrs}$ & 4 days & Rs. 23138 & .16290 \\
\hline Punjab & 34.13 & Rs.36000 & 875 & $25 \mathrm{hrs}$ & 4 days & Rs.36113 & .05067 \\
\hline Sindh & 50.67 & Rs.47000 & 1525 & $38 \mathrm{hrs}$ & 4 days & Rs.47631 & .00714 \\
\hline Foreigners & 39.47 & Rs. 120000 & 8200 & $30 \mathrm{hrs}$ & 5 days & Rs. 245250 & .00170 \\
\hline
\end{tabular}

Source: Survey.

The data was collected through a survey using a questionnaire by the enumerators from May 2007 until august this year. The data was collected randomly from 56 foreign and 275 Pakistani tourists (a total sample of 331). The information about their demographic characteristics, their current expenses, and their willingness to pay for environment was obtained. The survey was administered at three locations inside Chitral, i.e. Kalash Valley, Grram Chasma and Shandoor. Approximately, 10,000 tourists visited the area this year. This information was obtained from different hotels. Our sample size is about 3.3 percent of the total tourist's population. However, many researcher have used 1 percent of the population as the sample size. ${ }^{2}$

Economic theory does not designate any particular functional form. Different functional forms were tried and based upon the t-statistics and F-statistics of different models, the double log form was selected which is a widely used technique. It also accounts for the extreme values [Ward and Beal (2000)]. Moreover, the scatter plot of the VR and TC was used to decide about the functional form.

The model initially included the visitation rate per thousand of the population VRz as the dependent variable, the travel cost, education level, average age, and average income of the population as explanatory variables. However the average income of the population and education levels proved to be highly collinear and therefore they were dropped. The final model specified here is as follows:

$$
\operatorname{Ln} V R z=\operatorname{Ln} \beta 1+\beta 2 \operatorname{Ln} T C+\beta 3 \operatorname{Ln} A g e \quad \ldots \quad \ldots \quad \ldots \quad \ldots \quad \ldots
$$

${ }^{2}$ Himayatullah (2004) in his study on the valuation of the Eco-tourism has used one percent of the population as the sample size. 
Where, VRz was calculated, following the Lansdell and Gangadharan (2003) method for calculating the visitation rate. The total number of visitors from a zone in the sample(n) were divided the sample size $(\mathrm{Vt})$. This gave the proportion of visitors from each zone. This proportion was multiplied with the total number of visitors (T) this year which were 9223, which gave the estimated visits for each zone. The figure was divided by the zonal population $(\mathrm{POPz})$ and was multiplied by 1000 to obtain visitation rate from each zone. $\mathrm{VRz}=[\mathrm{nz} / \mathrm{Vt}] \mathrm{T} * 1000 / \mathrm{POPz}$.

For foreign visitors, instead of taking world population, the total numbers of foreign arrivals in Pakistan was considered as the foreign visitors population, because dividing it by world population might have given a value close to zero, and it is unfair to consider the probability of every foreigner to be the same for visiting Pakistan. Gosh and Kumar (2007) have used the same technique for calculating the foreign tourist visitation rate.

The average monetary cost (mc) considered for this study includes, the round trip per $\mathrm{km}$ petrol cost (as reported by the visitors) multiplied by the average distance travelled by the visitors from a zone, the monetary cost including food and accommodation.

In order to calculate the time cost of travelling to the site and time spent on the site, $1 / 2$ proportion of the reported zonal incomes were multiplied with the average time spent to the site and the average time spent on the site for each zone. The reason for selecting $1 / 2$ proportion of the zonal income is that about fifty percent of the respondent reported the opportunity cost of travelling. The total monetary cost and time cost were added to form travel cost for each zone (TCz).

Many studies suggest that age appears to be an important explanatory variable and it should be considered for TCM studies [Himayatullah (2004)]. In our case age was significantly related with the visitation rate and the partial correlation coefficient was used as an evidence to decide on this variable.

Equation (8) was used to obtain the results. By taking the anti-log of the result the VRz was obtained and subsequently was multiplied with the zonal population, hence the aggregate demand for the area was obtained as following.

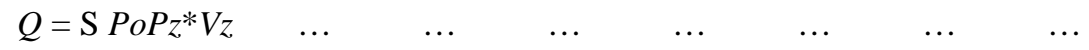

Where $P o P z$ is the population in thousand of the $z$ th zone and

$$
V z=f(T C, A g e)
$$

Nevertheless, it only denotes one point on the market demand equation and explains the current visitation in relation to the travel cost and other variable. Here a point worth mentioning is that the entry fee is zero in our case. Therefore, estimation of the consumer surplus requires that the entire demand curve should be estimated [Chotikapanich and Griffiths (1998)]. It requires $(T C z+P)$ must be replaced in the equation, so at the present the $Q$ is denoted by

$$
Q=\mathrm{S}\left(\left(\begin{array}{llllllll}
\text { Popz } f(T C z+P), \text { age }) & \ldots & \ldots & \ldots & \ldots & \ldots & (10)
\end{array}\right.\right.
$$

Where, $P$ is the hypothetical entry fee. By varying the entry fee the entire Marshallian demand curve can be obtained. This equation shows how the visitation will change if the Travel cost changes. 
The estimation of travel cost model provides the value of consumer surplus. Consumer surplus of an individual person is the difference between the actual price which they pay less the price they are willing to pay. The total surplus of an economic good such as a park or a resort is the sum of the individual surpluses. It implies that the area under the demand curve is the consumer surplus. In the absence of entry fee the entire area under the demand curve denotes the economic benefits to the consumers [Lansdell and Gangadharan (2003)]. Therefore the expression for the consumer surplus is as follow:

$$
C S=\int \mathrm{S}\left((\operatorname{Pop} z f(T C z+P), \text { age }) d P^{3} \quad \ldots \quad \ldots \quad \ldots \quad \ldots \quad \ldots \quad(11)\right.
$$

The consumer surplus (CS) so obtained shall be considered as approximate value because of the two reasons. Firstly, the value is the approximate area under the demand curve, and secondly, the true consumer surplus is the area under the compensated demand curve, but typically Marshallian demand curve is used to obtain the estimate of the CS.

\section{RESULTS AND DISCUSSION}

\subsection{Descriptive Statistics}

Table 1 reports the selected zones and the trip information of the zonal population. These zones have been selected based upon the distance from the site. These distances were reported by the respondents and these are the averages of the distance covered by a zonal population.

The maximum average age of the visitors was 50.67 years and they were from Sindh province which is also one of the zones in this study. The visitors from NWFP had the minimum age, i.e. 33.06.

Amongst the domestic tourist the respondents from Balochistan revealed the highest average income which was Rs 75000 p.m. Conversely, the average income of the visitors from NWFP was the lowest (Rs 25000 p.m). The average income of the foreign visitors was reported to be Rs 120,000 p.m.

On the average the foreign visitors covered a distance of $8200 \mathrm{~km}$ in $30 \mathrm{hrs} .87$ percent of them availed the road transport. The respondent from the Frontier zone covered the minimum distance and spent the minimum time to reach to the site. Maximum number of domestic tourist also travelled via roads.

The maximum average length of stay was of the foreign tourist which was five days, whereas visitors from Balochistan on the average spent minimum time on the site i.e. 2 days.

The average travel cost for each zone comprise the round trip monetary cost, other monetary cost such as food and accommodation, time cost of travelling to the site and the time cost of the time spent on the site. The foreign visitors had the highest average travel cost and almost lowest visitation rate, whereas amongst the domestic tourist, visitors from Sindh recorded the lowest visitation rate for the year. Conversely, the zone of NWFP had the lowest average travel cost and had the highest VR.

Table 2 exhibits the descriptive statistics of the sample respondents. The average age of all the visitors was 35.06 , whereas the average household size of the visitors was

${ }^{3}$ For details on Consumer Surplus, see Chotikapanich and Griffiths (1998). 
Table 2

Descriptive Statistics of Sample Respondents

\begin{tabular}{lc}
\hline Age (Years) Mean & 35.04 \\
Household Size & 5.25 \\
Gender & \\
$\quad$ Male & $89.4 \%$ \\
$\quad$ Female & $10.6 \%$ \\
Marital Status & \\
$\quad$ Married & $60.7 \%$ \\
$\quad$ Unmarried & $39.3 \%$ \\
Education & \\
$\quad$ None & $2.7 \%$ \\
Primary & $1.1 \%$ \\
Secondary & $14.8 \%$ \\
High Secondary & $12.3 \%$ \\
Bachelor & $25.9 \%$ \\
$\quad$ Post Graduates & $43.2 \%$ \\
How would you describe the quality of the site? & \\
$\quad$ Good & $86.4 \%$ \\
Poor & $9.6 \%$ \\
Any Other Source & $4.0 \%$ \\
If there is no other way but to raise the entry fee, would you be still visit the & \\
area? & \\
$\quad$ Yes & $80 \%$ \\
$\quad$ No & $20 \%$ \\
Entry Fee of Rs 20 & $36 \%$ \\
Rs 50 & $26 \%$ \\
\hline
\end{tabular}

5.26. About 89.4 percent of the respondents were male and as many as 61 percent were married. Almost 70 percent had a bachelor degree. Concerning the quality of the site, approximately 86 percent describe the quality of the sites to be good. Responding to a willingness to pay question, almost 80 percent agreed to visit even if entry fee is imposed. About 37 approved the fee to be Rs 20 per person, 26 percent of the respondent favoured a fee of Rs 50 per person, whereas just 20 percent of them preferred a fee of Rs 100 .

\subsection{Empirical Results}

The selection of variables for the estimated model is in accordance with the economic theory. The results of the correlation matrix show a value of 0.1284 between age and travel cost. Therefore, the result confirmed the absence of multicollinearity between the two variables. However, the correlation between the dependent variable (visitation rate), the travel cost and the age was found to be -0.491 and -0.55 respectively. Table 3 reports the pair wise correlation between the variables. The absence of multicollinearity among the explanatory variables, and significantly strong correlation of both the regressors with the dependent variable were the compelling reason for the specification of the model. 
Table 3

Correlation Matrix

\begin{tabular}{lccc}
\hline & Lnvr & lnage & lntc \\
\hline lnvr & 1.0000 & & \\
Lnage & -0.5509 & 1.0000 & \\
Lntc & -0.4906 & 0.1284 & 1.0000 \\
\hline
\end{tabular}

The theory does not suggest any particular functional form. Therefore we tried the linear and the double log form to analyse the problem. The results of both the models are reported in Table 4 and Table 5 respectively. The double log model was selected based upon the t-statistics and the F-statistics for both the models. Moreover, the scatter plot of Visitation Rate and Travel Cost was also used for the selection of the functional form.

Table 4

Regression Results of a Linear Model

\begin{tabular}{ccccccc}
\hline vZ & Coef. & Std. & Err. & $\mathrm{T}$ & $\mathrm{P}>|\mathrm{t}|$ & [95\% Conf. Interval] \\
\hline ag & -.0046277 & .004784 & -0.97 & 0.435 & -.0252115 & .0159562 \\
$\mathrm{tc}$ & $-3.12 \mathrm{e}-07$ & $3.74 \mathrm{e}-07$ & -0.83 & 0.493 & $-1.92 \mathrm{e}-06$ & $1.30 \mathrm{e}-06$ \\
\multirow{2}{*}{ cons } & .2511247 & .1854043 & 1.35 & 0.308 & -.5466057 & 1.048855 \\
\hline
\end{tabular}

Table 5

Regression Analysis Results

\begin{tabular}{lcc}
\hline Model Statistics & Values & Sig. \\
\hline Ln B1 & $27.57(6.36)$ & .024 \\
B2 & $-1.585(-6.84)$ & .021 \\
B3 & $-3.935(-3.31)$ & .08 \\
R & 0.98 & - \\
R $^{2}$ & 0.97 & - \\
Adjusted R & 0.95 & - \\
F- statistics & 38.68 & .025 \\
$P$-value for White Test for Hetroskedasticity & & 0.26 \\
\hline
\end{tabular}

Hetroskedasticity was checked using White Test. The insignificant $p$-value substantiated the absence of the Hetroskedasticity in the data. Moreover, to check the model specification, the predicted values (ZPRED) were plotted against the residual values (ZRESD) and no discernible pattern was found, which proved that the model is correctly specified. Though, it is an informal test, however, still it hints at correct specification. 
Graph: Visit Rate and Travel Cost

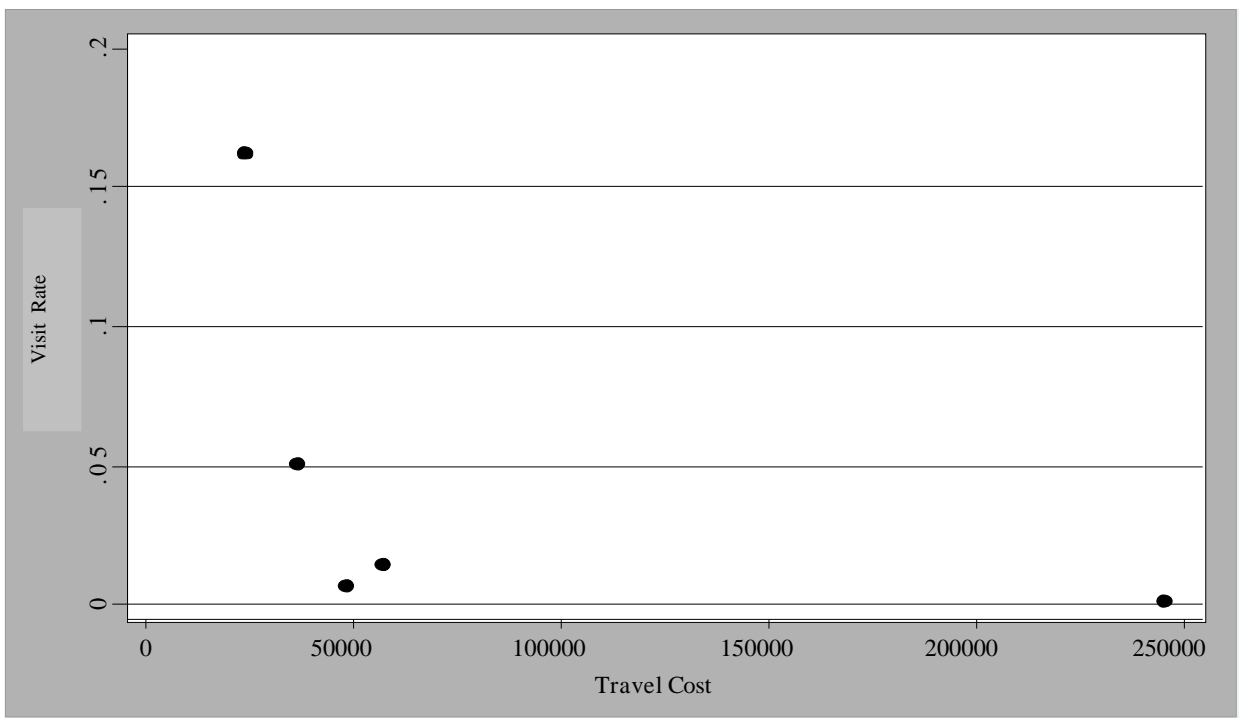

The results of the linear model are shown in Table 4 and it can be readily seen that the t-statistics for all the explanatory variables is insignificant. Table 5 report the regression results of the double log form. The sign of travel cost of the visitors to the visitation rate is negative. The coefficient sign validates the law of demand and it infers that the more the travel cost, the less would be the visitation rate originating from a zone. Hence, the demand of the recreation activities would be low for those visitors who live further away from the resort as compared to those who live nearby. The sign of the coefficient of the variable age is also negative and is in accordance with the expected sign. This implies that the visitation rate decreases as age increases. All the test statistics are significant and shows the reliability of the results. One measure of reliability of the results can be to compare the results of the estimated visits with the actual visits to the site. The estimated visits (Q) using Equation (10) are 9167 from the five zones, which is very close to the actual visits of 9223. The data on total visits was collected from the major hotels located inside the valley.

\subsection{Consumer Surplus}

The consumer surplus estimates have been obtained using the Chotikapanich and Griffiths method, the general procedure for which is outlined in equation (11), however the precise estimation was done using the following formula.

$$
C S=\left[e^{\beta 1} / \beta-1\right]+T C^{\beta+1}
$$

The consumer surplus or recreation value for the current year (2007) for Chitral has been estimated to be Rs 5225190. It is the annual recreational value generated by the Chitral valley every year. However, the recreational value does not reveal the non-use value of the resort and this should be considered as a lower bound. 


\section{CONCLUSION}

The study reveals the superior use value of the visits to Chitral Valley by domestic and foreign tourist, although this is a lower bound, yet quantifying the benefits associated with the recreational visits is an important step for lending a hand to the management for efficient resource allocation and to observe changes in the value of natural resources over time. The study is an important step in estimating the recreational benefit which can be used for cost benefit analysis of different policy options by government agencies, non government organisations. Sustaining resources can benefit people of current and future generation. In this sense, the study has wider applications. The study provides useful information for managing a natural resource like the present one.

The study has not recommended exact user fee for generating the resource, yet the important information ascertained, can help the local and provincial government for imposing the appropriate entry fee based on the WTP estimates of the study. Our study suggests imposing an entry fee for generating more resources.

Although eighty six percent of the visitors have expressed their satisfaction with the quality of the site, yet the study recommends that by improving the road, transport etc the flow of the tourist can be increased. Based upon high recreational value of the site, the study recommends more studies for achieving the Millennium Development Goal of sustainable development.

\section{REFERENCES}

Beal, D. (1995) A Travel Cost Analysis of the Value of Carnarvon Gorge National Park for Recreation Use. Review of Marketing and Agriculture Economics 63:2, 292-303.

Bhutan, Royal Government of (2002) Bhutan National Ecotourism Strategy. Thimphu: Department of Tourism.

Cesario, F. J. (1978) Value of Time in Recreation Benefit Studies. Land Economics 52:1, 32-41.

Chotikapanich, D. and W. E. Griffiths (1996) The Sensitivity of Consumer surplus Estimates to Funtional Form Specification. University of New England, Armidale. (Working Paper in Econometrics and Applied Statistics, No 94.)

Chotikapanich, D. and W. E. Griffiths (1998) Carnarvon Gorge: A Comment on the Sensitivity of Consumer Surplus Estimates. The Australian Journal of Agriculture and Resource Economics 43:3, 249-261.

Clawson, M. and J. L. Knetsch (1966) Economics of Outdoor Recreation. Baltimore: The John Hopkins Press.

Dixon, J. and P. B. Sherman (1991) Economics of the Protected Areas. Amibo 20, 68-74.

Dixon, J., K. Hamilton, S. Pagiola, and I. Segmestam (2001) Tourism and the Environment in the Caribbean. The World Bank. (Environment Economics Series Paper No. 80.)

Gillespie, R. (1997) Economic Value and Regional Economic Impact Minnamura Rain Forest Centre, Buddero, National Park, Economics and Regulatory Policy Reform Division, NSW National Parks and Wild Life Division.

Goha, Indrila and Santadas Ghosh (2007) Recreational Demand in Indian Sundarban: Estimation and Exploration. SANDEE's Fourteen Biannual Workshop at Katmandu, Nepal. 
Grandstaff, S. and J. A. Dixon (1986) Evaluation of the Lumpinee Public Park in Bangkok. In J. Dixon and M. M. Hafschmidt (eds.) Economic Valuation Technique for the Environment: A Case Study Workbook. Baltimore: The John Hopkins Press.

Gunatilake, H. M. (2003) Environmental Valuation: Theory and Application. Sri Lanka: Offset Printers Kandy.

Hanker, N., et al. (1997) Willingness to Pay for Borivli National Park: Evidence from a Contingent Valuation. Ecological Economics 105-122.

Hanley, Nick and Clive Spash (1995) Cost Benefit Analysis and the Environment. England: Edward Elgar Publishing.

Himayatullah (2004) Demand for Eco-tourism: Estimating Recreational Benefits from the Margalla Hills National Park in Northern Pakistan. South Asian Network for Development and Environmental Economics Katmandu, Nepal. (Working Paper No. 5-04.)

Hotelling, H. (1947) The Economics of Public Recreation: The Prewitt Report. Washington, DC: National Park Series.

Kaosa-ard, M., D. Patmasirimat, T. Panayotou, and J. R. Deshazo (1995) Green Financing: Valuation and Financing of Khao Yai National Park in Thailand, Bangkok: Thailand Research Institute.

Lansdell Nicola, and Lata Gangadharan (2003) Comparing Travel Cost Models and the Precision of their Consumer Surplus Estimates: Albert Park and Maroondah Reservoir. Blackwell Publishing Ltd.

Lumsdon, Les (1997) Tourism Marketing. International Thomson Business Press UK. 1-2.

McConnell, K. E. (1992) On-Site Time in the Demand for Recreation. American Journal of Agriculture Economics 74:4, 918-925.

Pakistan, Government of (2004) Pakistan Tourism Facts and Figures. Government of Pakistan.

Pankaj, P. K. (2004) Research Proposal Submitted for the Award of SANDEE Scholarship titled "Non Market Valuation of Bhutan's Composite as an International Eco-tourism Destination." ¿WWwW.sandeeonline.org

Smith, V. K. and Kaoru (1987) The Hedonic Travel Cost Model: A View from the Trenches. Land Economics 63:2, 179-192.

Walsh, R. G., L. D. Sanders, and J. R. McKean (1990) The Consumption Value of Travel Time on Recreation Trips. Journal of Travel Research, Summer, 17-24.

Ward, F. A. and D. Beal (2000) Valuing Nature with Travel Cost Models. Cheltanham: Edward Elgar.

Yapping, Du (1998) The Value of Improved Water Quality for Recreation in East Lake, Wuhan, China: Application of Contingent Valuation and Travel Cost Methods. Economy and Environment Programme for Southeast Asia, Tanglin Singapore. (EEPSEA Research Report Series.) 


\section{Comments}

First of all, much credit goes to the authors for selecting a very unique as well as a useful area to explore with reference to Pakistan. There are few observations: first of all sample size on which estimations are based is very small, that is only 3.3 percent of total visitors (which were 10,000 in the year the survey was conducted).

More elaboration is required on Equation 11, based on which authors have derived the recreation value. In addition, there is need to employ some statistical tests to assess the precision of these estimates. Very small sample size may have resulted in an upward biased estimated.

While going through this paper it was evident that authors have read many studies in this area. These studies have relied on a fairly large sample e.g., Landsdell and Gangadhran (2003). Similarly, study by Himayatulah (2004), only study done so far for Pakistan is a good study in terms of methodology and expression, and has used relatively large data set. This study also needs more clarity in mathematical expressions and in their derivation.

Pakistan Institute of Development Economics,

Afia Malik

Islamabad. 